\title{
Coronary heart disease beliefs and misconceptions among cardiac patients and people with chronic illness
}

\author{
Yu-Ping Lin ${ }^{1}$, Tsae-Jyy Wang ${ }^{2}$, Heng-Hsin Tung ${ }^{2}$, Gill Furze ${ }^{3}$ \\ ${ }^{1}$ Department of Nursing, Oriental Institute of Technology, New Taipei City, Taiwan \\ ${ }^{2}$ School of Nursing, National Taipei University of Nursing and Health Sciences, Taipei City, Taiwan \\ ${ }^{3}$ Faculty of Health and Life Sciences, Coventry University, Coventry, UK \\ Email: Fk014@mail.oit.edu.tw
}

Received 22 July 2011; revised 2 November 2011; accepted 13 November 2011

\begin{abstract}
What people believe about their illness may affect how they cope with it. It has been suggested that such beliefs may be commonly held within society. This cross-sectional investigation examined the cardiac beliefs and misconceptions among cardiac patients and people with chronic illness. Participants with a noncardiac chronic illness hold similar cardiac misconceptions to people with heart disease $(p=0.58)$. Both groups showed high agreement on "people with heart disease should take life easy" and "always avoid anything that might bring on angina”. People with chronic illness are more likely than cardiac patients to believe that "once you have had one heart attack, you are bound to have another one".
\end{abstract}

Keywords: Coronary Heart Disease; Chronic Illness; Illness Beliefs; Misconceptions

\section{INTRODUCTION}

Coronary heart disease (CHD) is the leading cause of morbidity and mortality in developed countries. In Taiwan, CHD has become the second leading cause of death. Secondary prevention is aimed at changing behavioural risk factors such as smoking and sedentary lifestyle. However, if patients hold misconceptions about their condition and how to cope with it that run counter to the advice being given, then concordance with risk factor reduction may be poor.

What people believe about their illness may affect how they cope with it. It has been suggested that such beliefs may be commonly held within society. The SelfRegulatory Model (SRM) assumes that the beliefs about health are based on personal previous experiences with illness and other information provided in the social environment [1]. Information about illness could come from health professionals (formal diagnosis or a routine health check) or from a lay referral system (family, friends, or the media) as people often access their social network to seek information and advice [2]. Such social messages influence how the individual interprets illness and the strategies developed to cope.

Research has focused on illness representations of individuals; however, health behaviours and illness experiences occur within a social context which is an important determinant of individual behaviours. Little is known about how the social context affects the representation of a health threat and ongoing plans and performance to cope with it. Moreover, misconceptions may sometimes be instilled or reinforced by family, society and/or health professionals [3-6]. The beliefs and misconceptions of these groups may influence the beliefs and behaviours of people with CHD. It is essential that health professionals and family are well informed and that health professionals are equipped to elicit commonly held cardiac misconceptions and dispel them. However, if cardiac misconceptions and maladaptive beliefs are commonly held within society, then there may be a constant source of contrary information.

People with heart disease and their relatives often have access to the same information from health professionals and may hold similar beliefs about heart disease [7-9]. In contrast, friends, the public or people with other chronic illness are less likely to receive information about living with heart disease and may have inappropriate beliefs and behaviours. Furze, Roebuck, Bull, Lewin, \& Thompson [10] found that angina beliefs of patients and their peers showed significant differences, where the peers held more misconceptions than those of patients.

Previous studies had investigated patients' and spouses' causal attributions and their outcome [8,11] but little is known about how people in society hold beliefs about heart disease. SRM presumes different aspects of the social environment will affect the two systems, representation of an illness threat and the development of coping plans, and the emotional responses to the illness threat and the development of coping plans for the man- 
agement of emotions, in different ways $[1,12,13]$. Threatened individuals may learn from or make comparisons to the opinions and abilities of others. Individuals would be receptive to opinions that are consistent with their preferred strategy for minimising the health threat [14]. This study is a first attempt to examine the beliefs about CHD of people with other chronic illnesses as they are likely to reflect societally held cardiac misconceptions.

\section{METHOD}

\subsection{Procedures}

The aim of this study was to discover which misconceived and maladaptive beliefs about heart disease are held by cardiac patients, and which by people with chronic illness. The study aimed to answer question: Do people with chronic illness hold similar misconceptions and maladaptive beliefs about heart disease as people with heart disease?

Consecutive patients attended outpatient clinics in Taipei, Taiwan were identified by hospital nurses who briefly explained the study. Patients who were interested to participate were then provided with a thorough explanation of the purpose of study by the first author, who also obtained oral and written consent. Each participant was interviewed face-to-face with a structured questionnaire in the outpatient clinic before or after consultation with the doctor in the clinics. Participants completed the questionnaire and immediately returned it to the researcher. Two hundred and thirty-eight people with heart disease and 290 people with chronic illness agreed to take part in the study.

\subsection{Participants}

The study was carried out in five outpatient clinics in a hospital in Taipei City. Patients with a diagnosis of CHD who attended outpatient clinics were identified by case note review undertaken by the researcher (Name). Those selected were adults of all ages with a diagnosis of CHD regardless of gender or ethnicity. Patients who have had a myocardial infarction (MI), angina pectoris, mild to moderate congestive heart failure (New York Heart Association, NYHA Classes 1-3), coronary artery disease (CAD) defined by angiography, a cardiac revascularisation procedure (coronary artery bypass grafting (CABG) or percutaneous transluminal coronary angioplasty (PTCA)), were included. Those in the acute stage of heart disease or unstable condition were excluded. People with chronic illness were recruited from outpatient clinics as the CHD patients' hospital. Adults (aged 18 years and over) who had received a diagnosis of a chronic disease (but not CHD) were included. Recruitment was undertaken, regardless of gender or ethnicity, among people who attended a consultation at the clinics.

\subsection{Survey Instrument}

The numbers of common cardiac beliefs and misconceptions held by the participants were assessed with the pilot York Cardiac Beliefs Questionnaire (pYCBQ). This ques tionnaire is designed to elicit beliefs about causation and coping in heart disease that are misconceived or potentially maladaptive. It consists of 24 statements about heart problems with answers scored at 0 (Disagree) and 1 (Agree). A high score on this questionnaire means that people held more misconceptions. Demographic details of age, gender, marital status and employment status were collected. Presence of comorbidities was assessed using the Charlson Comorbidity Index [15]. This index includes eleven chronic diseases: heart disease, congestive heart failure, peripheral vascular disease, cerebrovascular disease, chronic pulmonary disease, connective tissue disease, gastric disease, liver disease, diabetes, renal disease, hypertension and an option to add others.

\subsection{Validity and Reliability}

The pYCBQ has been shown to have good internal reliability (Cronbach's alpha score of 0.85 ) and stability ( $\mathrm{r}=$ 0.88) in a study of British people awaiting coronary artery bypass graft surgery [16]. The pYCBQ was translated into traditional Chinese characters and independently back translated into English to check for accuracy. The Chinese version of the questionnaire was tested with 11 Taiwanese students at [Name] University who did not participate in the main study. This testing helped to ensure the cultural and linguistic integrity of the questions. No major changes to the questionnaire were required. The pYCBQ also showed good internal consistency among the Taiwanese cardiac patients with a Cronbach's alpha coefficient of 0.73 .

\subsection{Ethical Consideration}

Ethical approval was given by the Research Governance Committee at a University. The study protocol was reviewed and approved by the Research Ethics Committee at the hospital and permission to conduct the study was also received from the director of the cardiovascular division. The information sheet provided a detailed explanation of the purpose of study. All participants were guaranteed strict confidentially, and they had been aware that they have right to withdraw without giving a reason. Written consent was gained from all participants.

\subsection{Data Analysis}

The data were analysed using Statistical Package for the Social Sciences 15.0 [17]. Descriptive statistical analyses were used to examine demographic data such age, gender, education, marital status, and work status. Differences 
between the two groups (people with heart disease and people with chronic illness) were conducted with the 2-tailed Student t test for continuous variables and with the Chi-square test for categorical variables. Fisher's exact test was used when cells had an expected count less than 5. Significance was set at 0.05 level and Bonferroni adjustment was adopted when undertaking multiple comparisons of the data.

Hierarchical multiple regression analyses were undertaken with pYCBQ as the dependent variable. The work status variable was reduced to working versus nonworking so that the data could be included in the regression analysis. The first block contained demographic variables (age, gender, work status and CCI) and the second block was group (as a dummy variable). This enabled the researchers to examine the effect of group on $\mathrm{PYCBQ}$ scores, controlling for differences in age, gender, work status and comorbidities. The independent variables were included in preliminary assumption testing to check for multicollinearity and singularity, outliers, normality, linearity, homoscedasticity and independence of residuals $[18,19]$, applying SPSS Explore and SPSS Regression.

\section{RESULTS}

\subsection{Demographic Details}

The equations are an exception to the prescribed specifications of this template. You will need to determine whether or not your equation should be typed using either the Times New Roman or the Symbol font (please no other font). Equations should be edited by Mathtype, not in text or graphic versions. You are suggested to use Mathtype 6.0 (or above version).

The 238 cardiac patients and 290 people with chronic illness were with mean ages of 71.00 (SD 10.63) years and 62.95 (SD 13.40) years. The most common chronic illnesses among chronic group were hypertension (84.1\%) and diabetes mellitus (16.2\%). There were differences in age, gender, work status and comorbidity between the two groups. People with chronic illness were more likely to be women, younger, have fewer comorbidities, and more likely to be in work than people with heart disease. Characteristics of the participating groups are presented in Table 1.

Table 1. Characteristics of the participating groups: people with heart disease and people with chronic illness.

\begin{tabular}{|c|c|c|c|c|c|c|}
\hline \multirow[b]{2}{*}{ Age: mean (SD) } & \multicolumn{2}{|c|}{ People w. chronic illness $n=290$} & \multicolumn{2}{|c|}{ People w. CHD n = 238} & \multirow{2}{*}{$\begin{array}{c}\mathrm{X}^{2} / \mathrm{t} \\
7.70\end{array}$} & \multirow{2}{*}{$\begin{array}{c}\text { Sig. } \\
<0.001\end{array}$} \\
\hline & 62.95 & $(13.40)$ & 71 & $(10.63)$ & & \\
\hline \multicolumn{7}{|l|}{ Gender: n (\%) } \\
\hline Male & 136 & $(46.9)$ & 139 & $(58.4)$ & \multirow{2}{*}{6.94} & \multirow{2}{*}{$0.008^{*}$} \\
\hline Female & 154 & $(53.1)$ & 99 & $(41.6)$ & & \\
\hline \multicolumn{7}{|l|}{ Marital status: n (\%) } \\
\hline Unmarried & 17 & (5.9) & 8 & (3.4) & \multirow{4}{*}{5.80} & \multirow{4}{*}{$0.122^{*}$} \\
\hline Married & 243 & $(83.8)$ & 192 & $(80.7)$ & & \\
\hline Divorced & 9 & (3.1) & 8 & (3.4) & & \\
\hline Widowed & 21 & $(7.2)$ & 30 & $(12.6)$ & & \\
\hline \multicolumn{7}{|l|}{ Work status: n (\%) } \\
\hline Working & 96 & $(33.1)$ & 47 & $(19.7)$ & & \\
\hline Retired & 142 & $(49.0)$ & 156 & $(65.5)$ & \multirow{4}{*}{19.08} & \multirow{4}{*}{$0.001^{*}$} \\
\hline Unemployed & 0 & & 2 & $(0.8)$ & & \\
\hline Off sick & 3 & $(1.0)$ & 1 & $(0.4)$ & & \\
\hline Other (housewife) & 49 & $(16.9)$ & 32 & $(13.4)$ & & \\
\hline \multicolumn{7}{|l|}{ Education: n (\%) } \\
\hline None/Never & 16 & (5.5) & 22 & $(9.2)$ & \multirow{6}{*}{14.51} & \multirow{6}{*}{$0.013^{*}$} \\
\hline Primary & 56 & $(19.3)$ & 60 & $(25.2)$ & & \\
\hline Secondary & 42 & $(14.5)$ & 35 & $(14.7)$ & & \\
\hline High & 65 & $(22.4)$ & 62 & $(26.1)$ & & \\
\hline College/University & 93 & $(32.1)$ & 54 & $(22.7)$ & & \\
\hline Graduate & 18 & $(6.2)$ & 5 & $(2.1)$ & & \\
\hline \multicolumn{7}{|l|}{ Ethnic origin: n (\%) } \\
\hline Taiwanese & 191 & $(65.9)$ & 163 & $(68.5)$ & \multirow{4}{*}{1.93} & \multirow{4}{*}{$0.619^{*}$} \\
\hline Hakka & 8 & (2.8) & 10 & $(4.2)$ & & \\
\hline Mainlanders & 89 & $(30.7)$ & 63 & $(26.5)$ & & \\
\hline Others & 2 & $(0.7)$ & 2 & $(0.8)$ & & \\
\hline Years since diagnosis: Mean (SD) & 6.31 & $(5.70)$ & 5.59 & $(4.73)$ & -1.54 & 0.124 \\
\hline CCI: Mean (SD) & 1.21 & $(0.64)$ & 1.42 & $(0.86)$ & 3.31 & 0.002 \\
\hline
\end{tabular}

SD = standard deviation. CCI: Charlson Comorbidity Index; CHD: Coronary Heart Disease; *Statistical significance after using Bonferroni correction; italics show significant comparison. 


\subsection{Differences in Cardiac Beliefs between People with Chronic Illness and with Heart Disease}

The overall mean score of pYCBQ for people with chronic illness was 13.80 (SD 2.61). In the analysis of item responses, the percentage of agreement with each item ranged from $2.4 \%$ to $98.6 \%$, with items 17 ("take life easy") and 18 ("avoid anything bring on angina") having the highest percent agreement among the people with chronic illness: $98.6 \%$ and $92.4 \%$, respectively. The highest percent of agreements among people with chronic illness were similar to those of people with heart disease.

There was no difference between patient and people with chronic illness groups in the total score on the pYCBQ (mean score people with illness, 13.80 [SD = 2.61]; mean score people with heart disease, 13.66, [SD $=2.89] ; \mathrm{t}(526)=-0.55, \mathrm{p}=0.58)$. In the hierarchical regression analysis (Table 2) there was no difference in the score of pYCBQ between groups after controlling for the effects of age, gender, work status and CCI (R square change: $0.5 \%, \mathrm{p}=0.111)$. The model was significant when all variables were included, $\mathrm{F}(5,522)=4.696, \mathrm{p}<$ 0.0005 , and explained $4.3 \%$ of variance. The demographic variables contributed $3.8 \%$, a small effect [20]; however, group did not made a unique contribution (beta $=0.073, \mathrm{p}=0.111$ ).

There were five item responses which differed between the two groups (items 3: "bound to have another attack", 4: “OK to disagree”, 7: "live life full”, 8: "not much you can do", and 11: "exercise") showing an alpha value of less than 0.05. Following the Bonferroni correction $(0.05 / 24=0.002)$, there were no significant differences between the groups, only item 3 ("bound to have another attack") was close to the significance level. The comparison of item responses on the PYCBQ of people with chronic illnesses and people with heart disease are shown in Table 3.

\section{DISCUSSION}

People with chronic illnesses and with heart disease held similar misconceptions and maladaptive beliefs about heart disease. From the results it can be seen that people with chronic illness and heart disease hold the highest percent agreement with the statements "People with heart disease should take life easy" and "It is important to avoid anything that might bring on angina or chest pain", and people with chronic illness were also slightly more likely to believe that "Once you have had one heart attack you are bound to have another one". This may reflect the perception of the need to discourage any physical fitness, exercise or excitement in people with heart disease. The results of this study were inconsistent with the findings of Furze, et al. [10] who reported that peers held more misconceptions than angina patients. The peers' mean age (61.62 years) in their study suggests that they were fairly likely to have at least one chronic illness (this was not reported in Furze et al.'s study) and that peers may also have access to information from health professionals. Moreover, it was not reported how close the relationship was, there may be other peers who had more influence on patients but who did not take part in the study.

The most common illnesses among the people with chronic illness group in the present study were hypertension and diabetes mellitus. Hypertension and diabetes mellituss are highly prevalent risk factors for the development heart disease [21-23]; therefore people with these illnesses may have received some information about heart disease and lifestyle advice to help reduce CHD risk. Nevertheless, this group of people with chronic illness did not have appropriate beliefs about heart disease, which may be due to some or all of the following reasons: 1) a lack of information from health providers, or 2) health education messages were not understood, or 3) there was a faulty interpretation of their experience.

Table 2. Hierarchical regression analysis on score of pYCBQ.

\begin{tabular}{|c|c|c|c|c|c|c|}
\hline Model & Variable & B & Beta & $\mathrm{t}$ & Sig. & Change in $\mathrm{R}^{2}$ \\
\hline \multirow[t]{5}{*}{1} & (Constant) & 10.58 & & 14.95 & $<0.001$ & \multirow{5}{*}{$0.038(\mathrm{p}<0.001)$} \\
\hline & Age & 0.03 & 0.13 & 2.34 & 0.020 & \\
\hline & Gender & 0.57 & 0.11 & 2.36 & 0.019 & \\
\hline & Work status & 0.08 & 0.01 & 0.24 & 0.812 & \\
\hline & CCI & 0.24 & 0.07 & 1.50 & 0.135 & \\
\hline \multirow[t]{6}{*}{2} & (Constant) & 10.48 & & 14.78 & $<0.001$ & \multirow{6}{*}{$0.005(\mathrm{p}=0.111)$} \\
\hline & Age & 0.03 & 0.16 & 2.69 & 0.007 & \\
\hline & Gender & 0.52 & 0.10 & 2.14 & 0.033 & \\
\hline & Work status & 0.06 & 0.01 & 0.18 & 0.859 & \\
\hline & CCI & 0.26 & 0.07 & 1.65 & 0.100 & \\
\hline & Group (patients) & -0.40 & -0.07 & -1.60 & 0.111 & \\
\hline
\end{tabular}

B = unstandardised coefficient, Beta = standardised coefficient; CCI = Charlson Comorbidity index. 
Table 3. Comparison of item responses on the PYCBQ of people with CHD and people with chronic illnesses.

\begin{tabular}{|c|c|c|c|c|}
\hline \multirow[b]{2}{*}{ Item statement } & \multicolumn{4}{|c|}{ n (\%) holding misconception } \\
\hline & $\begin{array}{l}\text { Cardiac patients } \\
(\mathrm{n}=238)\end{array}$ & $\begin{array}{l}\text { Person w. chro. Illn. } \\
(\mathrm{n}=290)\end{array}$ & $\mathrm{X}^{2}$ & Sig. $(\mathrm{df}=1)$ \\
\hline 1. A heart attack makes a weak area in the heart wall that can easily rupture & $176(73.9)$ & $202(69.7)$ & 1.19 & 0.276 \\
\hline 2. People who have heart problems should never get excited or upset & $188(79.0)$ & $242(83.4)$ & 1.72 & 0.190 \\
\hline 3. Once you have had one heart attack you are bound to have another one & $169(71.0)$ & $236(81.4)$ & 7.87 & 0.005 \\
\hline 4. It's OK to disagree with people with heart problems & $29(12.2)$ & $60(20.7)$ & 6.75 & 0.009 \\
\hline 5. People develop heart disease because of worry in their life & $138(58.0)$ & $165(56.9)$ & 0.06 & 0.802 \\
\hline 6. Angina is a kind of small heart attack & $189(79.4)$ & $218(75.2)$ & 1.33 & 0.249 \\
\hline 7. People with heart problems should live life to the full & $28(11.8)$ & $56(19.3)$ & 5.56 & 0.018 \\
\hline 8. There's not much you can do about heart problems & $117(49.2)$ & $113(39.0)$ & 5.53 & 0.019 \\
\hline 9. Any sort of excitement could be bad if you have heart problems & $202(84.9)$ & $237(81.7)$ & 0.93 & 0.336 \\
\hline 10. It's a good idea to check to see how you feel before doing something & $211(88.7)$ & $256(88.3)$ & 0.02 & 0.892 \\
\hline 11. Doing exercise can strengthen the heart muscle & $22(9.2)$ & $13(4.5)$ & 4.79 & 0.029 \\
\hline 12. Heart problems are a sign that you have a worn out heart & $187(78.6)$ & $230(79.4)$ & 0.04 & 0.863 \\
\hline 13. You can reduce your risk of more heart problems & $15(6.3)$ & $21(7.2)$ & 0.18 & 0.670 \\
\hline 14. Heart problems will definitely shorten your life whatever age you are & $154(64.7)$ & $203(70.0)$ & 1.67 & 0.196 \\
\hline 15. One of main causes of heart disease is stress & $196(82.4)$ & $251(86.6)$ & 1.77 & 0.183 \\
\hline 16. It is dangerous for people who have heart problems to argue & $182(76.5)$ & $243(83.8)$ & 4.46 & 0.035 \\
\hline 17. People with heart disease should take life easy & $229(96.2)$ & $286(98.6)$ & 3.14 & 0.076 \\
\hline 18. It is important to avoid anything that might bring on angina or chest pain & $221(92.9)$ & $268(92.4)$ & 0.04 & 0.846 \\
\hline 19. Heart problems are often caused by people’s lifestyle & $33(13.9)$ & $54(18.6)$ & 2.15 & 0.143 \\
\hline 20. People who have a heart problem should always avoid stress & $210(88.2)$ & $254(87.6)$ & 0.05 & 0.820 \\
\hline 21. Rest is the best medicine for heart problems & $189(79.4)$ & $212(73.1)$ & 2.85 & 0.092 \\
\hline 22. It is important for people with heart problems to carry on doing enjoyable things & $4(1.7)$ & $9(3.1)$ & 1.10 & 0.294 \\
\hline 23. Your heart is like a battery, the more you do, the faster it runs down & 159 (66.8) & 165 (56.9) & 5.42 & 0.020 \\
\hline 24. Changing your lifestyle can reduce your risk of more heart problem & $4(1.7)$ & $7(2.4)$ & 0.34 & 0.557 \\
\hline
\end{tabular}

Bonferroni correction $\mathrm{p}<0.05 / 24$ variables $=\mathrm{p}<0.002$.

A similar study was conducted by Rankin and Bhopal [24] to investigate the understanding of heart disease and diabetes in a South Asian community in the UK. For heart disease, $50 \%$ of 334 participants reported they did not understand the term and were unable to provide any description, $14 \%$ and $17 \%$ could not give a single cause and a preventive method, respectively. The results revealed that people in the community had a limited understanding of heart disease and diabetes. Misconceptions about stroke (chronic illness) has also been found people in the community, people believe in an increased risk associated with exercise [25]. A lack of understanding of illness may partly result in misconceptions about illness from their own experience and/or societal beliefs, for example, diabetes means the amount of sugar eaten, and heart attack is a sudden death.

Linkages to the social context were recognised on Leventhal's Self-Regulatory Model which states that social factors influence each variable involved in the representations of health threats and coping with illness. The social factors could involve the influence of cultural factors (ethnic and national), community (ecology, institutional roles, et cetera) and neighbourhood (family, friends, and social contacts) [26]. It is noteworthy in the present study that cardiac beliefs are commonly hold by a chronic illness group who did not have contact with people with heart disease, so this could be truly societal beliefs in Taiwan.

A significant example of social influence in Taiwan is that some people use certain traditional methods to protect themselves or to enhance health, such as herbal medicine or other traditional therapies (e.g. "Gin Pu" means eating herb with meat to revitalise the body). If any of these methods appeared effective to them, they would introduce it to other people even thought there is a lack of systematic evidence for these traditional therapies [27]. Individuals minimise the health threat and adopt coping methods to encounter the illness, it makes sense that the individuals would be receptive to opinions that are consistent with their preferred strategy for minimising distress [15]. Similarly, the person who had faulty beliefs and inappropriate coping methods about illness may often pass these on to others. Either misconceived or potentially maladaptive beliefs about an illness (heart dis- 
ease) or folk beliefs that belong to the personal world are likely to be accepted as normal in society [4].

The results of this study suggest that patients' misconceptions and maladaptive beliefs should be taken into account when planning education or other interventions designed to improve function. In addition the educational needs of the family should be included. Thus, education programmes are needed to target patients' and family beliefs about illness, and interventions to dispel misconceptions and overly negative views of their heart disease and recovery need to be designed and tested for efficacy.

Information about an illness comes from other people; formal diagnosis, healthcare providers, the lay referral system, and from family, friends and the media [1,4]. Such social messages influence how individuals interpret their illness and react to coping with illness. If no direct cause-effect relationship has been established, the public may believe the information reported by news media, family or neighbours which may be contradictory to evidence-based medical information. The media transmit information, for example, that all types of CHD are regarded as a heart attack, stress causes heart disease, that CHD means a worn-out heart and to take life easy once you have heart disease, and these misconceptions abound in Taiwanese society. The results of this study demonstrate that the Self-Regulatory Model acknowledges the role of social influence; in which the social environments are involved in shared beliefs, such as how individuals arrive at common representations of disease and suggests how common beliefs may affect the behaviours of the surrounding social network.

\section{LIMITATIONS}

The sample of people with chronic illness was recruited from clinics in Taipei, and therefore the results of this study cannot be generalised to other people with chronic illness and to societal beliefs as a whole. Another caution is the study was cross-sectional in design and thus no causal associations should be concluded between study variables, the directionality of these effects needs to be confirmed in future studies. Notwithstanding these limitations, the results of this study serve to highlight issues about people hold misconceptions about heart disease or inappropriate beliefs in coping, and this is important at these issues can then be made the focus of future public education campaigns or individual heart disease information sessions.

\section{CONCLUSION}

This study provides a preliminary insight into patients' misconceived and potentially maladaptive beliefs about heart disease as well as the societal views about heart disease from people with chronic illness. Patients hold incorrect beliefs which may have an important effect on a patient's physical and/or psychological outcomes. Healthcare providers need to elicit patients' misconceptions and target education to dispel them. Cardiac misconceptions are also commonly held by people with chronic illness, which demonstrates that people in the society share incorrect or negative beliefs about an illness. If people with CHD living in a community that reinforces maladaptive coping beliefs, then concordance with professional advice may be replaced over time with compliance with societal beliefs. There is a major and urgent need for promoting a general correction of misconceptions and of giving positive and realistic views of heart disease within society to dispel the myth of heart disease.

\section{ACKNOWLEDGEMENTS}

The authors would like to thank the patients who were willing to participate in this study.

\section{REFERENCES}

[1] Leventhal, H. and Cameron, L. (1987) Behavioral theories and the problem of compliance. Patient Education and Counseling, 10, 117-138. doi:10.1016/0738-3991(87)90093-0

[2] Ogden, J. (2007) Health psychology: A textbook. 4th Edition, Open University Press, Berkshire.

[3] Maeland, J.G. and Havik, O.E. (1987) Measuring cardiac health knowledge. Scandinavian Journal of Caring Sciences, 7, 23-31.

[4] Leventhal, H., Benyamini, Y., Brownlee, S., Diefenbach, M., Leventhal, E.A., Patrick-Miller, L. and Robitaille, C. (1997) Illness representations: Theoretical foundations. In: Petrie, K.J. and Weinman, J.A., Eds., Perceptions of Health and Illness, Harwood Academic Publishers, Amsterdam, 19-45.

[5] Lin, Y.-P., Furze, G., Spilsbury, K. and Lewin, R.J.P. (2008) Cardiac misconceptions: Comparisons among nurses, nursing students and people with heart disease in Taiwan. Journal of Advanced Nursing, 64, 251-260. doi:10.1111/j.1365-2648.2008.04802.x

[6] Angus, N., Patience, F., Maclean, E., Corrigall, H., Bradbury, I., Thompson, D.R., Atherton, I. and Leslie, S.J. (2011) Cardiac misconceptions in healthcare workers. European Journal of Cardiovascular Nursing, 8, 16.

[7] Stewart, M., Davidson, K., Meade, D., Hirth, A. and Makrides, L. (2000) Myocardial infarction: Survivors' and spouses' stress, coping and support. Journal of Advanced Nursing, 31, 1351-1360. doi:10.1046/j.1365-2648.2000.01454.x

[8] Figueiras, M.J. and Weinman, J. (2003) Do similar patient and spouse perceptions of myocardial infarction predict recovery. Psychology and Health, 18, 201-216. doi:10.1080/0887044021000057266 
[9] Leong, J., Molassiotis, A. and Marsh, H. (2004) Adherence to health recommendations after a cardiac rehabilitation prog ramme in post-myocardial infarction patients: the role of health beliefs, locus of control and psychological status. Clinical Effectiveness in Nursing, 8, 26-38. doi:10.1016/j.cein.2004.02.001

[10] Furze, G., Roebuck, A., Bull, P., Lewin, R.J.P. and Thompson, D.R. (2002) A comparison of the illness briefs of people with angina and their peers: A questionnaire study. BMC Cardiovascular Disorders, 2. doi:10.1186/1471-2261-2-4

[11] Joekes, K., Maes, S. and Warrens, M. (2007) Predicting quality of life and self-management from dyadic support and overprotection after myocardial infarction. British Journal of Health Psychology, 12, 473-489. doi:10.1348/135910706X118585

[12] Leventhal, H., Diefenbach, M. and Leventhal, E.A. (1992) Illness cognition: Using common sense to understand treatment adherence and affect cognition interactions. Cognitive Therapy and Research, 16, 143-163. doi:10.1007/BF01173486

[13] Leventhal, H., Brissette, I. and Leventhal, E.A. (2003) The Common-Sense Model of self-regulation of health and illness. In: Cameron, L.D. and Leventhal, H., Eds., The Self-Regulation of Health and Illness Behaviour, Routledge, London, 42-65.

[14] Croyle, R.T. and Hunt, J.R. (1991) Coping with health threat: Social influence processes in reactions to medical test results. Journal of Personality and Social Psychology, 60, 382-389. doi:10.1037/0022-3514.60.3.382

[15] Charlson, M.E., Pompei, P., Ales, K.L. and McKenzie, C.R. (1987) A new method of classifying prognostic comorbidity in longitudinal studies: Development and validation. Journal of Chronic Disease, 40, 373-383. doi:10.1016/0021-9681(87)90171-8

[16] Furze, G., Dumville, J.C., Miles, J.N.V., Irvine, K., Thompson, D.R. and Lewin, R.J.P. (2009) "Prehabilitation” prior to CABG surgery improves physical functioning and depression. International Journal of Cardiology, 132, 51-58. doi:10.1016/j.ijcard.2008.06.001

[17] SPSS Inc. (2006) SPSS based 15.0 for Windows user's guide. SPSS Inc., Chicago.

[18] Field, A. (2009) Discovering statistics using SPSS (Introducing statistical methods). Sage, London.

[19] Pallant, J. (2005) SPSS survival manual. A step by step guide to data analysis using SPSS for windows (version 12). 2nd Edition, Open University Press, New York.

[20] Cohen, J. (1988) Statistical power analysis for the behavioral sciences. Erlbaum, Hillsdale.

[21] Pasternak, R.C., Grundy, S.M., Levy, D. and Thompson, P.D. (1997). Task force 3: Spectrum of risk factors for CHD. Journal of the American College of Cardiology, 27, 978-990. doi:10.1016/0735-1097(96)87731-X

[22] British Cardiac Society, British Hypertension Society, Diabetes UK, Heart UK, Primary Care Cardiovascular Society and The Stroke Association (2005) JBS 2: Joint British Societies' guidelines on prevention of cardiovascular disease in clinical practice. Heart, 91, v1-v52. doi:10.1136/hrt.2005.079988

[23] Ryden, L., Standl, E., Bartnik, M., Berghe, G., Betteridge, J., Boer, M., et al. (2007) Guidelines on diabetes, prediabetes, and cardiovascular disease. European Heart Journal, 28, 88-136.

[24] Rankin, J. and Bhopal, R. (2001) Understanding of heart disease and diabetes in a south Asian community: Crosssectional study testing the "snowball" sample method. Public Health, 115, 253-260. doi:10.1038/sj.ph.1900777

[25] Sullivan, K. and Waugh, D. (2005) Stroke knowledge and misconceptions among survivors of stroke and a nonstroke survivor sample. Top Stroke Rehabilitation, 12, 72-81. doi:10.1310/TJK4-V5W9-R5T7-GLEH

[26] Leventhal, H., Rabin, C., Leventhal, E.A. and Burns, E. (2001) Health risk behaviours and aging. In: Birren, R. and Schaie, W., Eds., Handbook of the Psychology and Aging, 5th Edition, Academic Press, San Diego, 186214.

[27] Jeng, C., Chu, F.-L. and Tsao, L.-I. (2002) Empowering: The experiences of exercises among heart transplantation patients in Taiwan. Journal of Advanced Nursing, 40, 560-567. doi:10.1046/j.1365-2648.2002.02414.x 